\title{
PERSUASIVE EVIDENCE IN INDIA: AN INVESTIGATION OF THE IMPACT OF EVIDENCE TYPES AND EVIDENCE QUALITY
}

\author{
Jos Hornikx and Judith de Best
}

\begin{abstract}
Research on persuasive evidence types has been limited to Western cultures. Because Western systems of thought are claimed to be fundamentally different from Eastern systems of thought, the persuasiveness of evidence types was explored in one Eastern culture. Indians $(N=183)$ judged claims supported by different evidence types. Statistical, expert, and causal evidence were found to be equally persuasive as support for claims. Indians also appeared sensitive to evidence quality that was manipulated according to Western norms for reasonable argumentation: normatively strong evidence was more persuasive than normatively weak evidence. Findings are compared to results from studies conducted in Western cultures.
\end{abstract}

Key Words: culture, evidence, experiment, India, persuasiveness

For more than fifty years, researchers have been interested in the kinds of data that are most effective in supporting a claim (Reinard, 1988). When data are used as proof for claims, they can be considered evidence (cf. Reynolds \& Reynolds, 2002). Evidence has mostly been studied for claims that describe (future) events: factual claims or probability claims. Generally speaking, researchers have investigated the persuasiveness of evidence types by comparing claims (in a longer text or in isolation) supported by one or another type of evidence: anecdotal, statistical, causal, or expert evidence. Anecdotal, or story, evidence (Baesler, 1997) usually consists of an individual who has experienced the event described in the claim. Statistical evidence provides numerical data based on a large number of individuals who have experienced the event. Causal evidence provides a causal explanation of the event described, and, finally, expert evidence consists of a reliable and trustworthy expert who underscores the claim.

Anecdotal and statistical evidence have been most frequently studied. In Slater and Rouner (1996), for instance, anecdotal evidence consisted of a person who had experienced the problems described in the claim because of his alcohol consumption (namely, economic and career harm). An example of statistical evidence was that $25 \%$ of men who occasionally drank suffer from the problems described. Slater and Rouner (1996) found statistical evidence to be more effective at supporting claims than anecdotal evidence. In other studies, anecdotal and statistical evidence were found to be equally persuasive (e.g., Baesler, 1997), or anecdotal evidence was found to be most persuasive (e.g., Koballa, 1986). Research findings on the persuasiveness of these two types of evidence have been equivocal, partly because of large variations in manipulations of evidence (Kellermann, 1980). In order to summarize extant research on a given domain, a meta-analysis is well suited (e.g., Allen, 2009; Lipsey \& Wilson, 2001). Allen and Preiss (1997), using a meta-analysis, summarized the empirical studies that addressed the question whether statistical evidence is more or less persuasive than anecdotal evidence in support of claims. Based on 19 comparisons of

Jos Hornikx, Centre for Language Studies, Business Communication Studies, Radboud University Nijmegen; Judith de Best, Centre for Language Studies, Business Communication Studies, Radboud University Nijmegen. The study was presented at the Rhetoric in Society Conference in Leiden (the Netherlands) on January 23, 2009. The authors thank Hans Hoeken, Catherine Nickerson, and Frank van Meurs for their help. Correspondence concerning this article should be addressed to Jos Hornikx, Radboud University Nijmegen, Business Communication Studies, Erasmusplein 1, P.O. Box 9103, 6500 HD Nijmegen, the Netherlands. E-mail:j.hornikx@let.ru.nl 
statistical and anecdotal evidence, Allen and Preiss concluded that statistical evidence was generally more persuasive than anecdotal evidence. In a narrative review, which included the findings of more recent experiments, Hornikx (2005) supports this conclusion.

In recent studies with multiple message designs, in which participants judged a number of claims that were supported by different evidence types, findings are fairly homogeneous, and corroborate Allen and Preiss' (1997) conclusion: statistical evidence is more persuasive than anecdotal evidence (see Hoeken \& Hustinx, 2003, 2009; Hornikx \& Hoeken, 2007, Study 1). In Hoeken and Hustinx (2009, Study 1), for instance, participants judged the probability of 20 claims, which were supported by either statistical or anecdotal evidence. In general, participants judged claims that were supported by statistical evidence as more probable than claims supported by anecdotal evidence. Two other studies used the same research design to compare these two types of evidence with causal and expert evidence (Hoeken \& Hustinx, 2003; Hornikx \& Hoeken, 2007). Findings show that causal and expert evidence were more persuasive than anecdotal evidence (Hoeken \& Hustinx, 2003; Hornikx \& Hoeken, 2007, Study 1). In Hornikx and Hoeken (2007, Study 1), statistical evidence was not only more persuasive than anecdotal evidence, but also more persuasive than causal and expert evidence.

\section{Persuasive Evidence in Western Cultures}

Allen and Preiss (1997) observed that the experiments they included in their meta-analysis were all conducted with Western participants. They therefore suggest that future research should consider other cultures: "Whether other cultures with different expectations for forms of proof would reflect the same outcomes is unknown" (p. 129). In the early stages of research on evidence, researchers already have asked whether the persuasiveness of evidence may differ from culture to culture (McCroskey, 1969). Although researchers have regularly emphasized the relevance of this question (Greene \& Brinn, 2003; Reynolds \& Reynolds, 2002), it has not received a developed answer yet.

Only a few studies have been conducted on culture and evidence, all of which have compared Western cultures. First, Parrott, Silk, Dorgan, Condit, and Harris (2005) examined the perceived persuasiveness of statistical evidence in verbal or visual format among African Americans and European Americans. The two cultural groups perceived statistical evidence with a visual representation as equally persuasive as statistical evidence with a verbal representation. Second, Hornikx (2008) gave Dutch and French participants eight different claims, each followed by a list of four types of evidence. The participants ranked these different evidence types in terms of how persuasive they expected the evidence to be for others, starting with the most persuasive on rank 1, and so on. For the two cultural groups, the pattern was similar: participants expected statistical evidence to be most persuasive for others, followed by expert, causal, and anecdotal evidence. Hornikx and Hoeken (2007, Study 1), finally, investigated the actual persuasiveness of anecdotal, statistical, causal, and expert evidence in 20 claims that they presented to participants in France and the Netherlands. For both cultural groups, statistical, causal, and expert evidence were found to be more persuasive than anecdotal evidence. For the Dutch participants only, statistical evidence was also more persuasive than expert and causal evidence. Hornikx and Hoeken (2007, Study 2) also manipulated the quality of evidence. Evidence quality depends on the underlying argumentation scheme that is present when evidence supports claims. Evidence has a high quality (and is normatively strong) when it respects the norms associated with the 
argumentation scheme. For instance, for the argument by authority, a person's credibility, reliability, and relevance of the field of expertise in relation to the topic of the claim are important (Walton, 1997). Hornikx and Hoeken (2007, Study 2) manipulated expert evidence to have a high quality when the expert's position ensured credibility and reliability, and when her or his field of expertise was relevant to the claim's topic. Expert evidence had a low quality when the expert's field of expertise was irrelevant to the topic of the claim. The quality of statistical evidence was manipulated by reducing the number of cases in the evidence, which is important for the underlying argument by generalization (cf. Garssen, 1997). Hornikx and Hoeken (2007, Study 2) showed that Dutch participants, but not the French participants, were sensitive to the quality of both expert and statistical evidence. For the Dutch participants, normatively strong statistical and normatively strong expert evidence were more persuasive than normatively weak statistical and normatively weak expert evidence.

\section{Evidence AND Western-Eastern Systems of Thought}

The studies comparing different Western cultures indicate that culture can play a role in the persuasiveness of different evidence types. The insights that these studies provide are limited in scope because, as Allen and Preiss (1997) observed, the empirical research on evidence has been conducted in the United States and Europe only. It is unknown how persuasive the different types of evidence are in cultures other than Western cultures, such as cultures in the Eastern part of the world. The comparison between so-called Western and Eastern cultures has been very popular in cross-cultural research in general (e.g., Hofstede, 2001; Nisbett, 2003; Oyserman, Coon, \& Kemmelmeier, 2002), and in argumentation research in particular (e.g., Combs, 2004; Gillon, 2008; Oetke, 1996). It should be noted that researchers emphasize that, within these two broad categories, there exist important differences. For instance, Varnum, Grossmann, Katunar, Nisbett, and Kitayama (2008) demonstrated that the cognitive style of Americans and West Europeans was different from Central and East Europeans, even though all four are categorized as Western. Knight and Nisbett (2007) even showed that significant cognitive differences can exist within one culture, depending on a person's social class. Nevertheless, specific differences can consistently be observed between Western cultures on the one hand and Eastern cultures on the other.

One of the frameworks comparing these two broad cultural groups is the psychological notion of Western and Eastern systems of thought (Nisbett, 2003; Nisbett, Peng, Choi, \& Norenzayan, 2001). Western cultures, such as those in North America and Europe, are heavily influenced by ancient Grecian cultures (Nisbett, 2003). According to Nisbett et al. (2001), Westerners have a preference for analytic reasoning, which is an important heritage of the ancient Greek philosophers. Westerners are believed "to focus on attributes of the object to assign it to categories, and a preference for using rules about the categories to explain and predict the object's behavior" (p. 293). Eastern cultures, on the other hand, are influenced by Taoism, and are located in Asia (e.g., China, Japan, or India). Easterners are believed to have a preference for holistic thinking, which involves "an orientation to the context or field as a whole, including attention to relationships between a focal object and the field, and a preference for explaining and predicting events on the basis of such relationships" (Nisbett et al., 2001, p. 293).

Nisbett (2003) presents an overview of empirical research that consistently points to cultural differences between Westerners and Easterners in areas such as perception, causal 
inference, the fundamental attribution error, and reasoning. In the area of reasoning, which is in play when people judge claims and evidence, the study conducted by Norenzayan, Smith, Kim, and Nisbett (2002, Study 3) is relevant. That study compared the acceptance of claims similar to these two: "Germans are nice people" and "Poles are nice people." Both claims were supported by the same premise: "All Europeans are nice people." Both Westerners (Americans) and Easterners (Koreans) considered Germans to be a more typical instantiation of Europeans than Poles. For the Westerners, this difference in typicality did not affect their acceptance of the claims. Easterners, however, were more inclined to accept the claims when they contained typical rather than atypical instantiations.

The framework of systems of thought that compares Westerners with Easterners has a parallel in argumentation studies, as Combs (2004) makes a similar distinction between these two broad cultural groups when he compares the Western, Greco-Roman with the Eastern, Daoist view on argumentation. The Greco-Roman tradition focuses on rationality, and on discovering cause/effect relationships, principles, and objectivity. In the Daoist view, subjectivity is accepted because objectivity is considered impossible; this view concentrates on understanding the interactions and connections that exist between all elements. This also means that the role of argumentation is different: "Daoism includes a process view of argumentation that is relational rather than adversarial. Disputants engage in argumentation as a process of enlightenment, not to ascertain or test the grounds of particular truth claims" (Combs, 2004, p. 69). This distinction does not mean, however, that there are no similarities between the two views on argumentation. Eastern argumentation, for instance, has also been concerned with questions about what constitutes good and bad reasoning (e.g., Gillon, 2008; Tillemans, 2008).

\section{ReSEARCH Questions}

A considerable body of research reports on the persuasiveness of evidence types (e.g., Allen \& Preiss, 1997; Reinard, 1988; Reynolds \& Reynolds, 2002), but this is based on American and European studies only. In order to broaden insights into the persuasiveness of evidence types, it is important to investigate this in an Eastern culture (cf. Allen \& Preiss, 1997). Work on systems of thought (Nisbett, 2003; Nisbett et al., 2001) and argumentation (Combs, 2004) emphasizing differences between Westerners and Easterners makes it all the more relevant to explore how persuasive different evidence types are in an Eastern culture.

In this essay, India is taken as an example of an Eastern culture. Studies have empirically demonstrated Indians to reason more holistically than Westerners (e.g., Miller, 1984; Monga \& John, 2007). It should be noted at the outset that India is not expected to be representative for the overall group of Eastern cultures (cf. Jensen, 1992), because variations within Eastern cultures exist (e.g., Hofstede, 2001; Varnum et al., 2008). Moreover, people's social class has also been shown to play a role in differences in cognition within a single country. In fact, Knight and Nisbett (2007) demonstrated that working class Italians reasoned in a more holistic way than middle class Italians in the southern part of Italy. In the present study, therefore, only students were invited to participate in order to limit large variations in social class. The choice for students in the present study is typical for evidence research: in the studies reviewed in Hornikx (2005), more than 60\% is based on student samples only. This choice allows for a better comparison between the present study and earlier research findings. If, for example, the persuasiveness of evidence were explored in rural India, chances would be higher that evidence is perceived very differently than in Western 
studies-but such a result would be less meaningful as it might be attributed to social class and levels of education in addition to culture. Finally, it should be noted that students are not representative of the Indian population, as they have good mastery of the English language, which is not typical of Indians given that $39 \%$ of the Indian population is illiterate (Central Intelligence Agency, 2011). These issues will be commented on in the discussion.

This study compares the persuasiveness of different evidence types in India. Earlier research compared anecdotal, statistical, causal, and expert evidence (e.g., Hoeken \& Hustinx, 2003; Hornikx \& Hoeken, 2007). It should be noted that anecdotal evidence, which was found to be the least persuasive, is related to the same type of argument as statistical evidence, namely the argument by generalization. Both types of evidence use cases (one or more) to support the probability of a claim. If one is to compare different types of evidence, the comparison between statistical, causal, and expert evidence is more useful. The first research question therefore is:

RQ1: Is there a difference between the persuasiveness of statistical, causal, and expert evidence for students in India?

The case of statistical and anecdotal evidence is important, however, because it is related to the quality of evidence. Statistical and anecdotal evidence are-respectively-normatively strong and normatively weak evidence for the underlying argument by generalization. Researchers have stressed the role of evidence quality for the persuasiveness of evidence (e.g., Hoeken \& Hustinx, 2007; Reynolds \& Reynolds, 2002). The manipulations that were used in studies for normatively strong and normatively weak evidence (e.g., Hoeken \& Hustinx, 2007; Hornikx \& Hoeken, 2007, Study 2) are based on norms for reasonable argumentation. These norms have been developed in Western countries, such as the United States (e.g., Warnick \& Inch, 1989), Canada (e.g., Walton, 1997), and the Netherlands (e.g., Schellens, 1985). It is therefore insightful to investigate how Easterners (here: Indians) respond to variations in evidence quality based on these Western norms, and to find out whether normatively strong evidence is also more persuasive than normatively weak evidence to Easterners:

RQ2: Is evidence that is normatively strong according to Western norms more persuasive than evidence that is normatively weak for students in India?

\section{MeTHOD}

\section{Material}

A pool of 50 descriptive claims from Hornikx and Hoeken (2007), in which the consequences of actions or measures were described, was checked by the Indian Alliance Business Academy in Bangalore for suitability for the Indian society. In this first phase, a number of claims were not considered suitable, such as "Keeping pets leads to better mental health in the elderly." In a second phase, the remaining set of 31 claims was reduced on the basis of the claims' probability. Evidence is not useful for highly probable claims (they are accepted regardless of the evidence), nor for highly improbable claims (cf. Edwards \& Smith, 1996). In this phase, 12 claims were rated as moderately probable by six Indian students. This finding was corroborated in the main experiment $(N=183)$ : claims without evidence were rated as moderately probable on a 5 -point scale $(M=2.97, S D=0.70)$. An example of a claim used in the experiment is "Watching soaps reduces depression." Table 1 contains a list of all claims. 
TABLE 1.

LIST OF CLAIMS USED IN THE EXPERIMENT

Boys' performance at school can be improved by putting them next to girls in class.

Playing slow music in supermarkets increases sales.

Listening to classical music helps students to absorb a lot of knowledge in a short period of time.

Wearing a tie too tightly leads to reduced sight.

People's fear of flying can be decreased if they take part in a balloon flight.

If publicity agents watch cartoons that were popular in their youth, they will regain their creativity.

Playing computer games has a positive impact on people's sense of direction.

Riding a bike over bad, bumpy roads promotes stronger bones.

A walk during lunch breaks leads to higher work productivity in the afternoon.

Watching soaps reduces depression.

The regular consumption of pizzas reduces the risk of cancer.

The use of a lightweight mouse and regular relaxation reduce the risk of RSI for people who often work with computers for hours a day

For each of the 12 claims, different types of evidence were constructed. The operationalizations were inspired by Hoeken and Hustinx $(2003,2009)$ and by Hornikx and Hoeken (2007). In the statistical evidence, a percentage indicated how many of the cases had experienced the effect described in the claim. An example is "A study among 317 Indians showed that for $82 \%$ of the people who watch soaps regularly, depression was reduced." The various instantiations of statistical evidence had sample sizes ranging from 138 to 467 (depending on the nature of the claim), and percentages ranging from $71 \%$ to $82 \%$. For expert evidence, the operationalization consisted of a professor repeating the actual claim, such as in "According to Dr. Ramanathan from the University of Mumbai, a specialist in media psychology, watching soaps reduces depression.” In India, university professors are identified by the use of "Dr.". Different expert names (e.g., Dr. Goenka) and universities (e.g., University of Chennai) were used for each instantiation. The universities where the data were collected were not employed in the expert evidence operationalizations. Causal evidence, finally, consisted of an explanation of the causal relationship that was described in the claim. For the claim about soaps and depression, the causal evidence was "By regularly watching the fictitious lives of others in soap series, people become better at putting their own problems into perspective, which leads to them feeling less depressed."

In order to compare normatively strong with normatively weak evidence (RQ2), two comparisons were planned, one for the argument by generalization, and one for the argument by authority. For the argument by generalization, the comparison between statistical and anecdotal evidence is relevant. Statistical evidence respects the norms of argument by generalization if the number of cases in the evidence is large (which was the case in this study), whereas anecdotal evidence, which does not respect the norm of large numbers, can be considered normatively weak evidence (cf. Garssen, 1997). The operationalization of anecdotal evidence consisted of an example of one person who had experienced the consequence described in the claim. An example is "Since Sonali Khanna from Calangute started watching soaps, she has felt less depressed." For each instantiation, different names (e.g., Venkatesh Gupta) and geographical locations (e.g., Manali) were used.

For the argument by authority, the quality of evidence depends on the expert's credibility, reliability, and relevance of the field of expertise in relation to the topic of the claim (cf. Walton, 1997). In the example of expert evidence given above, the evidence is normatively strong because the expert's position ensures credibility and reliability, and because her or his field of expertise (media psychology) is relevant to the topic of the claim. The normatively 
weak expert evidence was operationalized to be relatively weak, because the experts were still professors but their fields of expertise were irrelevant to the claim. For the example above, the normatively weak expert was a professor in physiotherapy.

In sum, for each of the claims, the following types of evidence were constructed: statistical evidence, anecdotal evidence, causal evidence, normatively strong expert evidence, and normatively weak expert evidence.

\section{Participants}

One hundred eighty-three students from two universities participated. In order to better represent the country, one university was located in the northern part of India (New Delhi; $n=140$ ) and one in the southern part (Bangalore; $n=43)$. Students were on average 21.11 years old $(S D=2.78)$, with a range of 17 to 32 . Most of the participants were female $(60.1 \%)$. As will be further explained in the design of the study, six versions of the material were developed. Participants were randomly assigned to one of the six versions. The six groups of participants did not differ in their mean age $(F(5,177)=1.17, p=.31)$, or in the sex distribution $\left(\chi^{2}(5)=3.62, p=.61\right)$.

\section{Instrumentation}

The material was introduced as a study on social issues. The participants received 12 claims that were each followed by one type of evidence. Each set of a claim and evidence was followed by a probability measure. Participants rated the claims' probability on a 5-point semantic differential (very improbable - very probable) after they had read a repetition of the claim without evidence (cf. Hoeken \& Hustinx, 2003, 2009; Hornikx \& Hoeken, 2007). The instrumentation also contained a check for the perceived expertise of the normatively strong and normatively weak experts. For each expert, participants indicated their agreement with the claim that a given expert had enough expertise to make a judgment about the particular claim he supported (5-point Likert scale). ${ }^{1}$ The manipulation of normatively strong and normatively weak expert evidence was successful: professors with relevant fields of expertise $(M=3.16, S D=0.88)$ were considered having more expertise than professors with irrelevant fields of expertise $\left(M=2.92, S D=0.93 ; F(1,179)=9.47, p<.01, \eta^{2}=.05\right)$. The questionnaire ended with questions about participants' demographics: age, sex, nationality, and current education.

\section{Design}

The design of this study follows those of Hoeken and Hustinx $(2003,2009)$. The experiment had a within-subjects design: participants judged all types of evidence, and normatively strong as well as normatively weak evidence. Each participant received the 12 claims in the same order: two claims were supported by statistical evidence, two claims by normatively strong expert evidence, two claims by normatively weak expert evidence, two

\footnotetext{
${ }^{1}$ The use of single-item instruments is generally seen as a limitation (but see Bergkvist \& Rossiter, 2007). For the probability measure, Hoeken and Hustinx (2003) used three items in their pretest $(\alpha=.89)$, but noticed irritation among their participants who had to rate their probability judgments three times for a large number of claims. Therefore, one of the three items was selected here (cf. Hornikx \& Hoeken, 2007): very improbable - very probable. For the expertise measure, the single item was used for four experts, so expertise was in fact measured using four items (cf. Hornikx \& Hoeken, 2007). Moreover, if the object is concrete (here: the person who was described) and the attribute is concrete (here: expertise), multiple items are considered unnecessary (Rossiter, 2002).
} 
TABLE 2 .

THE PERSUASIVENESS OF TYPES OF EVIDENCE COMPARED TO CLAIMS WITHOUT EVIDENCE

\begin{tabular}{lcc}
\hline \hline & \multicolumn{2}{c}{ Persuasiveness } \\
\cline { 2 - 3 } Evidence type & $M$ & $S D$ \\
\hline Claims Without Evidence & 2.97 & 0.70 \\
Statistical Evidence & +0.24 & 0.91 \\
Expert Evidence & +0.19 & 0.89 \\
Causal Evidence & +0.18 & 0.92 \\
\hline \hline
\end{tabular}

claims by causal evidence, two claims by anecdotal evidence, and two claims without evidence. There were six versions of the material, which differed in the way in which the evidence types were connected to the 12 claims. A Latin square design ensured that, all versions taken together, a claim was supported by all six types of evidence. For instance, the first claim was followed by anecdotal evidence in version 1 , by statistical evidence in version 2 , by causal evidence in version 3 , by normatively strong expert evidence in version 4 , by normatively weak expert evidence in version 5 , and by no evidence in version 6 .

One type of evidence was the no-evidence condition where participants only received a claim (cf. Hoeken \& Hustinx, 2003, 2009). This control condition was used as a baseline to compute the persuasiveness of evidence. For each claim, an average probability score was computed when it was not supported by evidence. This was the baseline score (e.g., 3.05 on a 5-point scale). Next, for each probability score of a given claim with evidence (e.g., 3.25), this baseline score was subtracted, resulting in a persuasiveness score for evidence alone (e.g., $3.25-3.05=0.20$ ). The resulting difference score is the net effect of providing evidence in support of the claim. As indicated above, claims without evidence received an average score of $M=2.97(S D=0.70)$.

\section{Procedure}

Students were recruited at different locations on university campuses in New Delhi and Bangalore. Participation was voluntary. After the questionnaires had been collected, the research purpose was revealed, and participants were thanked for their cooperation. There were no disturbances during the experiment.

The analysis of the persuasiveness of evidence types and evidence quality is based on the computed difference scores (cf. Hoeken \& Hustinx, 2003, 2009). These scores indicate how much of a difference adding evidence in support of a given claim makes in comparison with that claim without evidence. A positive score implies that evidence makes claims more persuasive, and a score of 0.00 implies that claims with evidence are as persuasive as claims without evidence.

\section{Results}

Table 2 shows the mean persuasiveness of statistical, causal, and expert evidence. In order to address RQ1, the persuasiveness of these types of evidence was compared. An analysis of 
TABLE 3.

THE PERSUASIVENESS OF EVIDENCE QUALITY IN FUNCTION OF TYPE OF ARGUMENT COMPARED TO CLAIMS WITHOUT EVIDENCE

\begin{tabular}{llrc}
\hline \hline \multirow{2}{*}{ Evidence Quality } & \multicolumn{2}{c}{$\begin{array}{c}\text { Type of Argument } \\
\text { (Evidence) }\end{array}$} & \multicolumn{2}{c}{ Persuasiveness } \\
\cline { 3 - 4 } Claims Without Evidence & & $M$ & $S D$ \\
Strong & Generalization (Statistical) & 2.97 & 0.70 \\
Weak & Authority (Expert) & +0.24 & 0.91 \\
& Generalization (Anecdotal) & +0.19 & 0.89 \\
& Authority (Expert) & +0.04 & 0.90 \\
\hline \hline
\end{tabular}

variance showed that there was no main effect of evidence type on persuasiveness $(F(2$, $181)<1$ ). Statistical, causal, and expert evidence were equally persuasive. ${ }^{2}$

The second research question addressed the difference between normatively strong and normatively weak evidence. RQ2 was answered positively: there was a main effect of evidence quality on persuasiveness $\left(F(1,182)=7.53, p<.001, \eta^{2}=.04\right)$. Normatively strong evidence $(M=0.22, S D=0.65)$ was found to be more persuasive than normatively weak evidence $(M=0.04, S D=0.67)$. This main effect was not qualified by an interaction between evidence quality and type of argument (argument by generalization, argument by authority): $F(1,182)<1$. Table 3 gives the persuasiveness scores for strong and weak evidence in function of type of argument.

\section{Conclusion AND Discussion}

Empirical research on the persuasiveness of evidence types has so far been limited to American and European participants. The present study is the first exploration of the persuasiveness of evidence types and evidence quality for Eastern participants. Results show no statistically significant differences between statistical, causal, and expert evidence in India (RQ1). This pattern of the relative persuasiveness of the three types of evidence resembles findings found in similar Western studies (Hoeken \& Hustinx, 2003; Hornikx \& Hoeken, 2007).

The present study also investigated whether Indians were sensitive to variations in evidence quality based on Western norms for reasonable argumentation (RQ2). Results show that the Indian participants are more persuaded by normatively strong than by normatively weak evidence: normatively strong expert evidence was more persuasive than normatively weak expert evidence, and statistical evidence was more persuasive than anecdotal evidence. Studies with Westerners have also shown that normatively strong evidence can be more persuasive than normatively weak evidence (Hoeken \& Hustinx, 2007, 2009, Study 3; Hornikx \& Hoeken, 2007, Study 2), and-more specifically-that statistical evidence is more persuasive than anecdotal evidence (cf. Allen \& Preiss, 1997). The finding that the Indian participants are sensitive to variations in evidence quality does not necessarily imply that they have the same norms for strong evidence as Americans or Europeans. For instance, if statistical evidence is more persuasive than anecdotal evidence, this can be attributed to the criterion of sample size, but-alternatively-also to a possible

\footnotetext{
${ }^{2}$ Statistical power to detect differences between pairs of evidence types was larger than .995 for large $(d=.80)$ and medium effect sizes $(d=.50)$, and about .85 for a small effect size $(d=.20)$. Effect sizes were computed on the basis of Cohen (1988) with a correction for within-subject designs following Aron and Aron (1997).
} 
preference for statistical information. In order to determine what norms Indians have for strong evidence, future research should assess participants' cognitive responses, i.e., the thoughts that participants write down after having read claims with evidence. Researchers typically analyze the number of thoughts and the valence of the thoughts. The measurement of cognitive responses could be very useful in evidence research (Allen et al., 2000), in particular when researchers would also examine whether the responses reflect the application of the norms associated with normatively strong and normatively weak evidence, such as the norm of a large sample of cases. Such a study would deepen our insights into what constitutes persuasive evidence in India.

\section{The Present Study Compared to Western Studies on Evidence}

As the present study is the first to have explored the persuasiveness of evidence in a culture that is very different from cultures involved in earlier studies (US, Europe), it is interesting to examine how these results relate to earlier findings. In view of the fact that studies have demonstrated differences in the evaluation of persuasive evidence types between European countries (Hornikx \& Hoeken, 2007), it would not be surprising if the current results diverged from those of Western studies. In light of the sharp distinction made in psychology (Nisbett, 2003; Nisbett et al., 2001) and argumentation (Combs, 2004) between the Eastern and Western views on reasoning and argumentation, the similarity between the present findings and earlier, Western research on evidence may be regarded as striking. However, it is believed that the choice to study students and to study India may, at least partly, explain this similarity. In the first place, the participants in this sample resemble participants from earlier studies in a number of ways, namely level of education, age, social class, and literacy. Indian students are likely to be more similar to American, German, or Italian students than a representative sample of Indians is to representative samples of Americans, Germans, or Italians. In the second place, the Indian culture has not only been formed by Asian systems of thought (see Nisbett, 2003), but-much more recently-has also been influenced by the British colonization. With the imposed British educational system, it is likely that, to some degree, a Western system of thought has found its way in the Indian society. It is, of course, impossible to determine how each of these two influences may have affected the present results.

The implication of the present study is that Indian students seem to perceive the persuasiveness of evidence types and evidence quality in ways comparable to Western students. The similar findings may put culture and evidence more prominently on the research agenda. The present study may further stimulate the discussion about the role that Eastern and Western systems of thought play in argumentation (cf. Siegel, 1999; Tillemans, 2008). This study is exploratory, and its findings cannot be translated to samples other than students, and to Eastern cultures other than India. Nevertheless, it constitutes a first step in examining the persuasiveness of evidence in an Eastern culture. In order to gain more insights into the persuasiveness of evidence types and evidence quality in Eastern cultures, future research should consider other cultures, and other samples. When it comes to other cultures, it should be stressed, again, that India is taken as an example of an Eastern culture. Just as the United States is not representative of Western cultures, India is not representative of Eastern cultures (cf. Jensen, 1992). If differences in persuasive evidence can be detected between Western cultures which are as geographically close as France and the Netherlands (Hornikx \& Hoeken, 2007), the present Indian results can obviously not predict results in, 
say, Thailand or Japan. If the aim is to examine how persuasive evidence is in Eastern cultures, research in different Eastern cultures should be conducted before conclusions can possibly be drawn about persuasive evidence for Easterners. If the aim is to examine how persuasive evidence is in a specific Eastern culture, for example India, future research should examine samples other than student samples. These samples together may allow for results that can be generalized to the level of a specific culture. Finally, although the present study used a multiple message design that allows for better generalization than single message designs (e.g., Jackson, 1992), it still is one study with one operationalization of evidence types and evidence quality. Other claims and other operationalizations of evidence types should be considered in future studies.

\section{REFERENCES}

Allen, M. (2009). Meta-analysis. Communication Monographs, 76, 398-407.

Allen, M., \& Preiss, R. W. (1997). Comparing the persuasiveness of narrative and statistical evidence using meta-analysis. Communication Research Reports, 14, 125-131.

Allen, M., Bruflat, R., Fucilla, R., Kramer, M., McKellips, S., Ryan, D. J., \& Spiegelhoff, M. (2000). Testing the persuasiveness of evidence: Combining narrative and statistical forms. Communication Research Reports, 17, 331-336.

Aron, A., \& Aron, E. N. (1997). Statistics for the behavioral and social sciences: A brief course. Upper Saddle River, NJ: Prentice-Hall.

Baesler, E. J. (1997). Persuasive effects of story and statistical evidence. Argumentation and Advocacy, 33, 170-175.

Bergkvist, L., \& Rossiter, J. R. (2007). The predictive validity of multiple-item versus single-item measures of the same constructs. Journal of Marketing Research, 44, 175-184.

Central Intelligence Agency (2011). The World Factbook. Retrieved July 14, 2011, from https://www.cia.gov/ library/publications/the-world-factbook/geos/in.html

Cohen, J. (1988). Statistical power analysis for the behavioral sciences (2nd ed.). Hillsdale, NJ: Lawrence Erlbaum.

Combs, S. C. (2004). The useless-/usefulness of argumentation: The Dao of disputation. Argumentation and Advocacy, $41,58-70$.

Edwards, K., \& Smith, E. E. (1996). A disconfirmation bias in the evaluation of arguments. Journal of Personality and Social Psychology, 71, 5-24.

Garssen, B. J. (1997). Argumentatieschema's in pragma-dialectisch perspectief: Een theoretisch en empirisch onderzoek [Argumentation schemes in a pragma-dialectic perspective: A theoretical and empirical study]. Amsterdam: IFOTT.

Gillon, B. S. (2008). An early Buddhist text on logic: Fang Bian Xin Lun. Argumentation, 22, 15-25.

Greene, K., \& Brinn, L. S. (2003). Messages influencing college women's tanning bed use: Statistical versus narrative evidence format and a self-assessment to increase perceived susceptibility. Journal of Health Communication, 8, 443-461.

Hoeken, H., \& Hustinx, L. (2003). The relative persuasiveness of different types of evidence. In F. H. van Eemeren, J. A. Blair, C. A. Willard, \& A. F. Snoeck Henkemans (Eds.), Proceedings of the Fifth Conference of the International Society for the Study of Argumentation (pp. 497-501). Amsterdam: Sic Sat.

Hoeken, H., \& Hustinx, L. (2007). The influence of additional information on the persuasiveness of flawed arguments by analogy. In F. H. van Eemeren, J. A. Blair, C. A. Willard, \& B. Garssen (Eds.), Proceedings of the Sixth Conference of the International Society for the Study of Argumentation (pp. 625-630). Amsterdam: Sic Sat.

Hoeken, H., \& Hustinx, L. (2009). When is statistical evidence superior to anecdotal evidence in supporting probability claims? The role of argument type. Human Communication Research, 35, 491-510.

Hofstede, G. (2001). Culture's consequences: Comparing values, behaviors, institutions, and organizations across nations (2nd ed.). Thousand Oaks, CA: Sage.

Hornikx, J. (2005). A review of experimental research on the relative persuasiveness of anecdotal, statistical, causal, and expert evidence. Studies in Communication Sciences, 5, 205-216.

Hornikx, J. (2008). Comparing the actual and expected persuasiveness of evidence types: How good are lay people at selecting persuasive evidence? Argumentation, 22, 555-569.

Hornikx, J., \& Hoeken, H. (2007). Cultural differences in the persuasiveness of evidence types and evidence quality. Communication Monographs, 74, 443-463.

Jackson, S. (1992). Message effects research: Principles of design and analysis. New York: Guilford Press.

Jensen, J. V. (1992). Values and practices in Asian argumentation. Argumentation and Advocacy, 28, 153-166.

Kellermann, K. (1980). The concept of evidence: A critical review. Journal of the American Forensic Association, 16, $159-172$.

Knight, N., \& Nisbett, R. E. (2007). Culture, class and cognition: Evidence from Italy. Journal of Cognition and Culture, 7, 283-291.

Koballa, T. R. (1986). Persuading teachers to reexamine the innovative elementary science programs of yesterday: The effect of anecdotal versus data-summary communications. Journal of Research in Science Teaching, 23, 437-449.

Lipsey, M. W., \& Wilson, D. B. (2001). Practical meta-analysis. Thousand Oaks, CA: Sage.

McCroskey, J. C. (1969). A summary of experimental research on the effects of evidence in persuasive communication. Quarterly Journal of Speech, 55, 169-176. 
Miller, J. G. (1984). Culture and the development of everyday social explanation. Journal of Personality and Social Psychology, 46, 961-678.

Monga, A. B., \& John, D. R. (2007). Cultural differences in brand extension evaluation: The influence of analytic versus holistic thinking. Journal of Consumer Research, 33, 529-536.

Nisbett, R. E. (2003). The geography of thought: How Asians and Westerners think differently . . . and why. London: Nicolas Brealey.

Nisbett, R. E., Peng, K., Choi, I., \& Norenzayan, A. (2001). Culture and systems of thought: Holistic versus analytic cognition. Psychological Review, 108, 291-310.

Norenzayan, A., Smith, E. E., Kim, B. J., \& Nisbett, R. E. (2002). Cultural preferences for formal versus intuitive reasoning. Cognitive Science, 26, 653-684.

Oetke, C. (1996). Ancient Indian logic as a theory of non-monotonic reasoning. Journal of Indian Philosophy, 24, 447-539.

Oyserman, D., Coon, H. M., \& Kemmelmeier, M. (2002). Rethinking individualism and collectivism: Evaluation of theoretical assumptions and meta-analyses. Psychological Bulletin, 128, 3-72.

Parrott, R., Silk, K., Dorgan, K., Condit, C., \& Harris, T. (2005). Risk comprehension and judgments of statistical evidentiary appeals: When a picture is not worth a thousand words. Human Communication Research, 31, 423-452.

Reinard, J. C. (1988). The empirical study of the persuasive effects of evidence: The status after fifty years of research. Human Communication Research, 15, 3-59.

Reynolds, R. A., \& Reynolds, J. L. (2002). Evidence. In J. P. Dillard, \& M. Pfau (Eds.), The persuasion handbook: Developments in theory and practice (pp. 427-444). Thousand Oaks, CA: Sage.

Rossiter, J. R. (2002). The C-OAR-SE procedure for scale development in marketing. International Journal of Research in Marketing, 19, 305-335.

Schellens, P. J. (1985). Redelijke argumenten: Een onderzoek naar normen voor kritische lezers [Reasonable arguments: A study in criteria for critical reading]. Dordrecht, The Netherlands: Foris.

Siegel, H. (1999). Argument quality and cultural difference. Argumentation, 13, 183-201.

Slater, M. D., \& Rouner, D. (1996). Value-affirmative and value-protective processing of alcohol education messages that include statistical evidence or anecdotes. Communication Research, 23, 210-235.

Tillemans, F. J. F. (2008). Introduction: Buddhist argumentation. Argumentation, 22, 1-14.

Varnum, M. E. W., Grossmann, I., Katunar, D., Nisbett, R. E., \& Kitayama, S. (2008). Holism in a European cultural context: Differences in cognitive style between central and east Europeans and Westerners. Journal of Cognition and Culture, 8, 321-333.

Walton, D. N. (1997). Appeal to expert opinion: Arguments from authority. University Park, PA: Pennsylvania State University Press.

Warnick, B., \& Inch, E. S. (1989). Critical thinking and communication: The use of reason in argument. New York: Macmillan. 